\title{
Carreira e piso nacional salarial para os profissionais da educação básica
}

Dalila Andrade Oliveira*

\begin{abstract}
RESUMO: Criar ou revisar os planos de carreira dos profissionais da educação é uma demanda urgente. Este texto traz informações, oriundas de pesquisas, sobre aspectos pouco explorados do contexto escolar e dedica especial atenção aos funcionários de escola. Assim, dedica a última parte à descrição e discussão de dados de um survey com funcionários de escola em um estado brasileiro.
\end{abstract}

Palavras-chave: Carreira docente. Profissionais da educação. Funcionários de escola.

\section{Introdução}

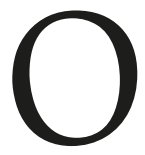

s dirigentes municipais e estaduais de educação encontram-se nos dias atuais diante da tarefa de criar ou revisar os planos de carreira dos profissionais da educação que atuam em suas redes. Muitos esforços devem ser concentrados no sentido de buscar cumprir essa determinação legal que acarreta muitos desafios considerando a realidade brasileira no seu conjunto. Este texto busca contribuir com essa discussão trazendo informações oriundas de pesquisas que lançam luzes sobre aspectos pouco explorados do contexto escolar. $\mathrm{O}$ artigo busca inicialmente situar a problemática na atualidade, referenciando-se em estudos nacionais e internacionais que abordam a questão, recorrendo posteriormente a dados de pesquisas sobre os docentes para demonstrar alguns dos desafios apontados na literatura específica e identificados nas pesquisas sobre a realidade escolar que devem ser considerados, apesar de pouco lembrados, na elaboração dos planos de carreira. O texto dedica especial atenção aos funcionários de escola como sujeitos desse processo, justamente por compreender que

* Doutora em Educação. Professora Titular de Políticas Públicas em Educação da Universidade Federal de Minas Gerais (UFMG), coordenadora da Rede Latino-americana de Estudos Sobre Trabalho Docente (Rede Estrado) e pesquisadora PQ-1A/CNPq. Belo Horizonte/MG - Brasil. E-mail: <dalila@ufmg.br>. 
muito pouco se sabe sobre a realidade desses trabalhadores. Para tanto, destina a última parte da discussão à apresentação e análise de dados de recente survey realizado com funcionários de escola no estado de Pernambuco.

Apesar de ser uma exigência antiga, prevista no Artigo 206 da Constituição Federal de 1988 e reforçada na Lei de Diretrizes e Bases da Educação (LDB nº 9.394) de 1996, a aprovação do atual Plano Nacional de Educação (PNE), em junho de 2014, Lei nํㅜㄹ. 13.005, de 2014, coloca certa urgência nessa tarefa ao determinar, na sua Meta 18, que devem ser asseguradas, "no prazo de 2 (dois) anos, a existência de planos de Carreira para os(as) profissionais da educação básica e superior pública de todos os sistemas de ensino e, para o plano de Carreira dos(as) profissionais da educação básica pública, tomar como referência o piso salarial nacional profissional, definido em lei federal, nos termos do inciso VIII do art. 206 da Constituição Federal" (BRASIL, 2014)

Essa determinação legal, a rigor, implica que, até o final de junho deste ano (2016), os estados e municípios brasileiros tenham que implementar seus planos, que todas as redes públicas de ensino, incluindo a educação superior, devem estabelecer carreiras adequadas às diretrizes nacionais. No caso da educação básica, esses planos devem garantir o valor do piso salarial nacional como vencimento básico inicial para esses profissionais e, ao mesmo tempo, promover a equiparação salarial destes com os demais trabalhadores com mesmo nível de formação. Considerando que são os recursos do Fundo de Manutenção e Desenvolvimento da Educação Básica e de Valorização dos Profissionais da Educação (Fundeb) que têm garantido o pagamento do Piso Nacional Salarial Profissional aos que atuam na educação básica em redes públicas e que sua vigência é por tempo determinado, a discussão sobre os planos de carreira e salários de profissionais da educação nos remete necessariamente a um debate muito mais amplo sobre o financiamento da educação brasileira.

\section{Situando a problemática}

Considerando ser o Brasil um país federativo que conta com 26 estados, um Distrito Federal e 5570 municípios, distribuídos em cinco regiões geográficas que apresentam entre si significativas diferenças econômicas, sociais, culturais e políticas, e que cada ente federado tem relativa autonomia, inclusive em matéria educacional, a regulamentação de planos de carreira para a educação básica apresenta-se como questão bastante complexa e dependente da capacidade de negociação e acertos entre os envolvidos, o que é variável com a correlação de forças do momento. Os profissionais da educação básica no Brasil são contratados e remunerados pelos estados e municípios, o que resulta em grande desigualdade salarial e de condições de trabalho entre professores das diferentes regiões do país, pois, além de variar com a capacidade de financiamento de cada ente, 
cada um tem liberdade para criar e definir suas próprias carreiras e planos salariais, a despeito da legislação federal definir diretrizes de carreira docente em nível nacional (CNE. Res. no 2, de 2009) e Piso Salarial Profissional Nacional (Lei no 11.738, de 2008). Isso se reflete também na infraestrutura dos estabelecimentos de ensino, ou seja, as condições de acolhimento das crianças e jovens nas creches e escolas públicas brasileiras variam muito no que se refere às condições oferecidas.

Por tais razões, constata-se uma grande variedade de carreiras nas redes públicas de ensino brasileiras, o que não seria um problema grave se o país apresentasse maior equilíbrio entre seus municípios e estados. Da totalidade dos municípios brasileiros, $71 \%$ têm até 20 mil habitantes e reúnem 17,6\% (ou 32,5 milhões de pessoas) da população total. Na outra ponta, apenas 36 municípios (0,6\%) têm mais de 500 mil habitantes e reúnem 28,0\% (51,6 milhões de pessoas) da população. Aliado ao fator distribuiç̧ão desigual da população, observa-se a desigualdade da capacidade de arrecadação desses municípios e estados, o que faz com que tenhamos um país extremamente desigual e com grande fragmentação social e educativa (Oliveira, 2011: p. 27).

Portanto, a Meta 18 do PNE é bastante audaciosa para um país com as dimensões e discrepâncias do Brasil. Se considerarmos ainda as distâncias existentes entre as condições de trabalho, carreira e salários dos profissionais da educação básica e superior e também as contradições próprias da organização federativa do país, a Meta fica ainda mais difícil de ser alcançada na sua integralidade. Essa diversidade de situações impõe a exigência de diagnósticos claros e de metodologia compatível para lidar com os diferentes casos e possibilitar o monitoramento por parte do Estado e da sociedade do cumprimento da lei.

Contudo, essa não é uma discussão técnica, ela é antes de tudo política e exige o empenho dos diferentes níveis de governo e o acerto em torno de condições objetivas que assegurem uma consequente planificação.

A despeito de que essa meta do PNE tenha vindo como resposta às exigências de maior valorização dos profissionais da educação básica, com o estabelecimento de carreiras mais atrativas e equilibradas em âmbito nacional, dada a grande disparidade de oferta de condições de trabalho, carreira e salários entre municípios e estados brasileiros, como já comentado, não podemos concebê-la apenas como uma pauta imposta pelo movimento sindical, ela é uma exigência comprovada por pesquisas acadêmicas para se obter a realização de uma educação que possa atender às expectativas da sociedade.

Lamentavelmente essa discussão ganha destaque na agenda nacional justamente no momento em que o país passa por um período de instabilidade política, o que dificulta em muito o processo. O governo interino que assumiu o comando do poder executivo, por um período de até 180 dias, apesar de seu caráter interino e de ter como chefe de Estado o vice-presidente eleito na mesma candidatura encabeçada pela presidenta da república Dilma Rousseff (2014-2018), tem promovido uma brusca reorganização do 
Estado extinguindo ministérios e órgãos públicos já consolidados e anunciando medidas que vão na contramão do programa de governo que o elegeu. Essas medidas podem não só pôr em risco a discussão sobre a Meta 18 do PNE como comprometer o conjunto da Lei $\mathrm{n}^{\mathrm{o}}$ 13.005, de 2014, pois o que vem sendo articulado no Congresso Nacional, principal promotor do processo de Impeachment da presidenta Dilma, já nos indica retrocessos em pontos importantes das políticas sociais e da agenda educacional.

O PMDB, partido do presidente interino Michel Temer, lançou em outubro de 2015 um programa intitulado "Uma ponte para o futuro" que, partindo de uma análise da situação econômica com ênfase alarmista dada à "estagnação econômica e ao esgotamento fiscal do Estado", busca justificar a defesa dos cortes públicos em políticas sociais. O referido programa põe em risco importantes conquistas sociais, ao defender a necessidade de "acabar com as vinculações constitucionais estabelecidas como nos gastos com saúde e educação" ${ }^{\prime}$. Ao defender medidas dessa natureza, o Programa afronta a Carta Magna brasileira, retira dela sua autoridade, garantida pelo princípio da supremacia da Constituição, e confere todo o poder ao Congresso Nacional. Aponta para um estado de grande instabilidade, em que a sociedade fica à mercê das decisões do Congresso. Não só desrespeita a Constituição da República como a própria ordem constitucional, atribuindo poderes extremos ao Congresso Nacional, para além daqueles para os quais foi eleito - não nos esqueçamos de que não se trata de um congresso constituinte -, como se pode observar na seguinte passagem do Programa:

“O fim de todas as indexações inclusive para salários e benefícios previdenciários e tudo o mais (...) A cada ano, na votação do orçamento, o Congresso em conjunto com o Executivo decidirá sobre os reajustes".

Particularmente, essa "medida" põe em risco o piso salarial dos profissionais da educação básica e dos servidores públicos em geral, além de apresentar sérias ameaças às suas carreiras.

Alguns acontecimentos recentes no Congresso Nacional sinalizam nessa direção.

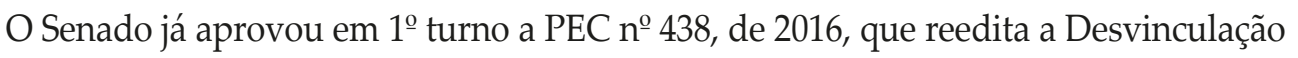
de Receitas da União (DRU) na educação e que cria as Desvinculações de Receitas dos Estados e Municípios (DRE e DRM), representando cortes nos recursos públicos dedicados à educação.

Somam-se a isso os riscos colocados à Lei nº 12.858, de 2012, que dispõe sobre a destinação para as áreas de educação e saúde de parcela da participação no resultado ou da compensação financeira pela exploração de petróleo e gás natural, com a aprovação do PLS nº 131, de 2015, que revoga a participação obrigatória da Petrobras na exploração do petróleo da camada do pré-sal, propondo alterações na Lei nº 12.351, de 22 de dezembro de 2010, que rege o tema. A proposta original é de autoria do senador José Serra (PSDB-SP), atual ministro de Relações Exteriores do governo interino, e contou 
com o substitutivo do senador Romero Jucá (PMDB-RR), que foi ministro do planejamento desse mesmo governo, mas obrigado a deixar o cargo por envolvimento em escândalo de corrupção.

Esses cortes orçamentários podem comprometer na sua origem o PNE, pois sem a garantia do financiamento, prevista na sua Meta 20, as outras dezenove metas podem não se efetivar. As condições para a implantação na totalidade dos estados e municípios brasileiros de planos de carreira para os profissionais de educação dependem de uma distribuição orçamentária melhor e mais justa, que possa capacitar os municípios e estados a responderem com eficiência às exigências de dotar as creches e escolas públicas de profissionais com formação compatível, com condições de trabalho adequadas, salários minimamente atraentes e com possibilidades de se desenvolver na carreira. Portanto, esta não é em definitivo uma discussão técnica que poderá ser resolvida independente do contexto político mais amplo.

De todo modo, mesmo reconhecendo as dificuldades do momento, este artigo se propõe a discutir alguns desafios específicos e imediatos para o cumprimento da Meta 18 na educação básica, ancorando-se em dados de pesquisas realizadas no contexto educacional brasileiro.

\section{Desafios para a organização dos planos de carreira}

A discussão sobre as mudanças nas carreiras tradicionais tem sido objeto de vários campos do conhecimento. A Sociologia das Profissões tem se dedicado à compreensão de como processos mais amplos, tais como a reestruturação produtiva e o emprego de novas tecnologias, as mudanças culturais, entre outros fatores, têm interferido nas formas tradicionais de se conceber as carreiras profissionais e como isso tem afetado as identidades docentes. (Rodrigues, 2002; Dubar, 1997). No campo da administração empresarial, esse é um tema recorrente, já que traz mudanças que afetam diretamente seu objeto central.

Balassiano; Ventura e Fontes Filho (2004), discutindo a evolução do conceito de carreira segundo Chanlat (1995), vão afirmar que a abordagem moderna de carreira surge em decorrência de mudanças sociais, tais como a feminização do mercado de trabalho, a elevação dos graus de instrução, a cosmopolitização do tecido social, a afirmação dos direitos dos indivíduos, a globalização da economia e a flexibilização do trabalho, entre outros. Para os autores, apesar de mais democrático, o moderno modelo de carreira se caracteriza pela instabilidade, descontinuidade e horizontalidade, em contraposição ao modelo tradicional baseado na carreira preponderantemente feita por um homem pertencente aos grupos socialmente dominantes, marcada por certa estabilidade e progressão linear vertical, com relativa estabilidade no emprego (Chanlat, 1995, p. 72). Nessa 
perspectiva tradicional, os benefícios são direitos assegurados e as organizações empregadoras devem assumir a responsabilidade pelas carreiras de seus empregados. Em síntese, a carreira é da empresa, pois é ela que permite os acessos e gerencia o desenvolvimento. E o sucesso na carreira tradicional pode ser medido pelo quão alto se chegou à hierarquia da organização.

Os mesmos autores constatam que essa mudança necessariamente não significou progresso e bem-estar para as pessoas, que se tornam as responsáveis por suas próprias carreiras. E afirmam ainda que, apesar de persistirem em organizações de grande porte a carreira do tipo burocrático, a tendência é de que essas organizações flexibilizem cada dia mais suas estruturas e a forma de ascensão, passando a valorizar atributos como o saber, a criatividade e o capital de relações.

As concepções de carreira e formas de remuneração, no caso específico da educação, podem refletir posições e interesses conflitantes. Observa-se, por exemplo, certa tendência, em alguns municípios e estados brasileiros, de adoção de políticas de gestão que levam em consideração o mérito pessoal, a produtividade e a responsalibilização dos professores pelo seu próprio desenvolvimento profissional e defendem abertamente pagamentos diferenciados. Essa tendência, já posta em prática em algumas redes públicas no País, estão ancoradas no modelo de Nova Gestão Pública (NGP) que defendem a chamada modernização das profissões, fundamentadas nas políticas de accountability, em contraposição às formas tradicionais, baseadas na estabilidade, na progressão hierárquica e na valorização dos títulos e da experiência.

Como já afirmado, dada a organização federativa do Estado brasileiro e seus desequilíbrios, sobretudo regionais, a organização dos planos de carreira dos profissionais da educação básica na atualidade é bastante dispersa e variada. Encontrando-se desde planos que contemplam o conjunto dos profissionais da educação quanto aqueles que apenas referem-se aos profissionais do magistério.

A partir da demanda provocada pela necessidade do cumprimento da Meta 18 do PNE, o Ministério da Educação (MEC), nos últimos anos, veio desenvolvendo algumas ações para amparar tecnicamente a discussão, sobretudo através da sua Diretoria de Valorização dos Profissionais da Educação da Secretaria de Articulação com os Sistemas de Ensino do MEC (Divap/Sase). Por meio de estudo dos planos de carreira dos 26 estados, do Distrito Federal e das 26 capitais brasileiras, promovido pela Divap/ Sase, foi evidenciada uma grande diversidade de critérios e formatos de planos. Com esses estudos, o MEC desenvolveu o Sistema de Apoio à Gestão dos Planos de Carreira e Remuneração ${ }^{2}$ que se dirige a prestar assistência técnica aos dirigentes municipais e estaduais de educação básica.

O que se espera em termos gerais com a organização da carreira dos profissionais da educação básica em nível nacional é melhorar as condições de trabalho e remuneração desses profissionais e com isso aumentar a atratividade da profissão docente no País. 
O desinteresse dos jovens pelos cursos de licenciatura tem sido evidenciado em estudos mais recentes e o pouco interesse pela profissão docente tem sido uma preocupação em âmbito internacional. Em 2005, a Organização para a Cooperação e Desenvolvimento Econômico (OCDE) publicou um estudo intitulado "O papel crucial dos docentes: atrair, formar e reter professores de qualidade", que retrata muito bem essa preocupação em âmbito mundial. Notam-se também, na literatura acadêmica, pesquisas em diferentes contextos nacionais que revelam preocupações baseadas na percepção, por parte dos professores, do seu estatuto e sua condição, como profissionais desmoralizados, sofrendo pelo não reconhecimento do seu trabalho e com a deterioração de suas condições de realização. (Esteve, 1995; Tenti-Fanfani, 2005; Demailly, 2009; Malet, 2009)

A preocupação com a atratividade aparece intimamente vinculada à percepção de baixa valorização da profissão por diferentes fatores, desde a pouca procura pelos cursos de licenciatura (FCC, 2009; Gatti \& Barreto, 2009; Gatti, Barreto e André, 2011; Leme, 2012; Duarte, 2013) até o abandono da carreira (Esteves, 1995: Codo, 2002). Em geral, esses estudos fazem referência ao sentimento dos professores de que possuem uma imagem depreciada da profissão e de suas atividades, atribuídas ao tratamento que recebem dos governantes, aos seus baixos salários, às condições pouco adequadas em que trabalham, ao pouco apoio vindo das famílias e ao desrespeito dos alunos. Esses são fatores que têm levado a desgastes prematuros desses profissionais (Gonçalves, 2003; Jardim, Barreto \& Assunção, 2007) e ao declínio do entusiasmo com a carreira escolhida, bem como ao abandono da profissão.

Sendo assim, podemos compreender a Meta 18 do PNE como uma conquista legal que reflete uma preocupação generalizada com a crise de atratividade sofrida pela profissão docente e a busca de certa recuperação do reconhecimento social desta, como resultante de políticas de valorização de suas condições de trabalho e remuneração. Outros fatores convergem na mesma direção, ou seja, da urgência de se estabelecer planos de carreira mais atrativos para os profissionais da educação. São eles: a necessidade de renovação dos quadros das redes públicas de educação básica e as mudanças na organização do trabalho escolar que fizeram emergir novos docentes que não são contemplados nos tradicionais planos de carreira.

A partir de dados de pesquisa, este texto procura explorar um pouco mais a discussão, buscando evidenciar aspectos pouco conhecidos (ou considerados) no cotidiano dos que trabalham nas creches e escolas públicas brasileiras.

A pesquisa Trabalho docente na educação básica no Brasil (TDEBB) ${ }^{3}$, nas suas fase $1 \mathrm{e}$ 2, coordenada pelo Grupo de pesquisa sobre política educacional e trabalho docente da Universidade Federal de Minas Gerais (Gestrado/UFMG), constituiu-se de uma iniciativa de conhecer a realidade de quem trabalha nas creches e escolas de redes públicas estaduais e municipais do País, sendo a primeira grande enquete a pesquisar os docentes das três etapas constitutivas da educação básica: educação infantil, ensino fundamental 
e ensino médio ${ }^{4}$ Para tanto, foram realizados dois surveys, sendo o primeiro nos anos de 2009 e 2010, com 8.795 entrevistas a sujeitos docentes ${ }^{5}$ da educação básica de sete estados brasileiros: Espírito Santo, Goiás, Minas Gerais, Pará, Paraná, Rio Grande do Norte e Santa Catarina e o segundo, a partir da pesquisa realizada no estado de Pernambuco, no ano de 2013, tendo sido entrevistados 981 professores e 612 funcionários de escola.

Esses dados nos ajudam a compreender um pouco melhor o que vem ocorrendo nas creches e escolas de diferentes redes públicas no Brasil, levando em consideração a percepção de seus próprios profissionais.

A pesquisa teve como uma de suas hipóteses orientadoras a constatação da emergência de uma nova divisão técnica do trabalho na escola. Tendo como categoria central o trabalho docente, abarcando tanto os sujeitos nas suas complexas dimensões, experiências e identidades, quanto as condições em que as atividades são realizadas nesses estabelecimentos, buscou compreender as atividades e relações que envolvem o cotidiano escolar.

A partir de estudos anteriores (Oliveira, 2004; Tenti Fanfani, 2005), a pesquisa partiu da premissa de que os professores se sentem muito demandados no seu trabalho e, com frequência, veem-se como responsáveis pelo desempenho de seus alunos e da escola. Estudos precedentes (Oliveira, 2000) permitiram saber que as escolas públicas, especialmente aquelas situadas em regiões mais vulneráveis socialmente, passaram a responder por importantes políticas sociais que atendem aos alunos e suas famílias, e, por tal razão, tiveram de se adequar a novas realidades que foram repercutindo em mudanças nos seus papéis tradicionais. À medida que se tornam mais complexas as demandas às quais as escolas devem responder, também se tornam mais complexas as atividades dos docentes.

O sistema espera preparo, formação e estímulo do sujeito docente para exercer o pleno domínio da sala de aula e para responder às exigências que chegam à escola no grau de diversidade que apresentam e na urgência que reclamam. (Oliveira, 2004)

Como se pode observar, no estudo anteriormente citado, realizado pela OCDE (2005), a sociedade contemporânea demanda que os estabelecimentos e os seus docentes estejam em condições de responder de forma eficaz às necessidades dos alunos oriundos de meios sociais e linguísticos diferentes, de lutar contra o fracasso escolar, de ser sensíveis às questões culturais, de igualdade de sexo, de estimular a tolerância e a coesão social, entre outras demandas. Para responder a essas exigências da sociedade e da economia, os docentes devem também estar em condições de desenvolver a autonomia dos alunos e o interesse de perseguir sua aprendizagem ao longo da vida. (Lessard, Kamanzi et Larochelle, 2013/2)

No caso brasileiro, a Constituição Federal de 1988, ao estabelecer como princípio no seu Artigo 206, Inciso VI, a gestão democrática do ensino público, respondendo aos anseios dos movimentos sociais no campo educacional, reforça novas exigências para 
a escola e para os docentes. Eles devem participar da gestão escolar, tanto na condição de gestores eleitos por seus pares como na representação junto aos conselhos e na elaboração da proposta pedagógica. O trabalho docente passa a contemplar, a partir das mudanças na legislação oriundas desse princípio, além das atividades em sala de aula, as reuniões pedagógicas, a participação na gestão e no planejamento pedagógico, o envolvimento com a comunidade, entre outras atividades.

Acresce-se a isso as iniciativas de educação inclusiva na escola regular, a ampliação recente da cobertura da educação infantil no sistema educacional, os programas de educação de tempo integral, entre outros, que acabam por demandar e inserir no contexto escolar novos sujeitos docentes. Tais mudanças têm resultado em reorganização do trabalho escolar, fazendo emergir nova divisão técnica do trabalho nas unidades educacionais; o que é flagrante nos milhares de estabelecimentos que adotam o Programa Mais Educação (PME) e repercutido diretamente sobre a identidade docente.

Entretanto, esses novos docentes permanecem invísiveis para as estatísticas oficiais e as políticas públicas para a educação e não estão na maioria das vezes contemplados nos planos de carreira e salários dos profissionais da educação. Esses novos docentes clamam por maior profissionalização, tanto no que se refere às oportunidades de formação e titulação quanto no que se relaciona ao reconhecimento legal de sua condição.

Nos dois surveys realizados na TDEBB, aproximadamente $30 \%$ dos respondentes docentes não são nomeadamente professores. Nos oito estados em que a pesquisa se realizou, identificamos uma grande diversidade de outras funções docentes que variam de acordo com a dependência administrativa e com a etapa de atendimento. Especialmente na educação infantil, são muitas as denominações dadas aos docentes, as mais frequentes são educadores infantis, auxiliares de creches, auxiliares de ensino, assistente de educação infantil , entre outros.

Nas escolas que adotam programas de educação em tempo integral, os novos docentes são contratados como oficineiros, estagiários, apoio ou, às vezes, os próprios professores são renomeados nas suas novas funções, como, por exemplo, o professor comunitário (Clementino, 2013).

Outra questão que demanda atenção é a renovação geracional dos profissionais que atuam nas redes públicas. Nos dados relativos aos perfis de nossos respondentes, observou-se que a média de idade dos docentes entrevistados estava entre 39 e 41 anos, (40,6 anos no conjunto dos sete estados e 39,7 anos em Pernambuco), sendo estes , na sua maioria, do sexo feminino ( $82 \%$ ). Considerando que os docentes iniciam, em média, sua vida profissional por volta dos 20 anos de idade, temos então quase metade da população docente com, aproximadamente, 20 anos de trabalho, ou seja, já muito perto de se aposentar. A legislação vigente permite a aposentadoria de professoras de educação básica com 25 anos de contribuição social e idade mínima de 50 anos de idade e de professores de educação básica com 30 anos de contribuição e idade mínima de 55 anos de 
idade. Então, a questão da atratividade se torna mais preocupante quando consideramos esta dimensão geracional da profissão.

Por outro lado, é necessário ponderar que a Meta 18 se refere a planos de carreira para os profissionais da educação e não para os profissionais do magistério. Esta amplitude dada aos planos exige que sejam contemplados todos os profissionais da educação previstos em lei, isto é, aqueles que são acolhidos pela Lei no 12.014 , de 2009, que altera o artigo 61 da LDB nº 9.394, de 1996, discriminando as categorias de trabalhadores que se devem considerar profissionais da educação, definindo ainda as exigências de formação para seu exercício, como se pode observar:

Art. 61: Consideram-se profissionais da educação escolar básica os que, nela estando em efetivo exercício e tendo sido formados em cursos reconhecidos, são:

I - professores habilitados em nível médio ou superior para a docência na educação infantil e nos ensinos fundamental e médio;

II - trabalhadores em educação portadores de diploma de pedagogia, com habilitação em administração, planejamento, supervisão, inspeção e orientação educacional, bem como com títulos de mestrado ou doutorado nas mesmas áreas;

III - trabalhadores em educação, portadores de diploma de curso técnico ou superior em área pedagógica ou afim.

Parágrafo único. A formação dos profissionais da educação, de modo a atender às especificidades do exercício de suas atividades, bem como aos objetivos das diferentes etapas e modalidades da educação básica, terá como fundamentos:

I - a presença de sólida formação básica, que propicie o conhecimento dos fundamentos científicos e sociais de suas competências de trabalho;

II - a associação entre teorias e práticas, mediante estágios supervisionados e capacitação em serviço;

III - o aproveitamento da formação e experiências anteriores em instituições de ensino e em outras atividades. (BRASIL, 2009)

A Lei atribui à formação específica o critério fundamental na definição dos que podem ser considerados profissionais da educação, sendo assim, a formação deverá ter centralidade como um dos componentes orientadores dos planos de carreira.

A maioria dos entrevistados no primeiro survey da TDEBB possui nível de escolaridade superior, a maior parte é constituída por aqueles que fizeram curso de licenciatura $(55 \%)$, seguida pelos que cursaram pedagogia (35\%). Os que fizeram curso normal superior e outros tipos de graduação equivalem a $5 \%$ da categoria. Importante observar que $52 \%$ informaram ter realizado algum curso em nível de pós-graduação.

Apesar de a formação ser um importante critério para a progressão na carreira, ela não deve ser o único, pois a experiência refletida no tempo de serviço também deve contar como um estímulo à permanência. Nos dois surveys realizados na TDEBB, 
constatou-se que as redes públicas contam com professores com bastante experiência, na sua maioria com mais de 5 anos de serviço. Quando perguntados sobre os aspectos mais valorizados no plano de cargos e salários, para aqueles contemplados por um, eles informaram ser a titulação e o tempo de serviço, atingindo $83 \%$ e $73 \%$ dos entrevistados, respectivamente.

Outra variável importante a ser considerada nos planos de carreira dos profissionais da educação básica é a exclusividade a uma unidade educacional. Estudos e pesquisas têm demonstrado que os professores trabalham em mais de uma unidade educacional. A pesquisa Talis ${ }^{6}$ (2013) que se refere aos professores do $6^{\circ}$ ao $9^{\circ}$ ano do ensino fundamental constatou que $25 \%$ deles trabalham em mais de uma escola, sendo cerca de $20 \%$ em duas escolas e $5 \%$ em três ou mais escolas. Na TDEBB, que pesquisou docentes das três etapas da educação básica - educação infantil, ensino fundamental e ensino médio, essa proporção é de $46 \%$ que trabalham em mais de uma unidade educacional, sendo que $37 \%$ afirmaram atuar em duas unidades, $7 \%$ em três e 3\% em quatro ou mais.

$\mathrm{O}$ vínculo com a instituição é muito importante para a continuidade do trabalho, o amadurecimento do coletivo e para o desenvolvimento de laços com a comunidade. A dedicação exclusiva a uma mesma unidade educacional é sem dúvida um fator de enriquecimento da condição profissional docente.

Ainda é muito importante considerar o vínculo empregatício, pois, apesar de a EC n 53 , de 2006 prever o ingresso na carreira mediante concurso público, as redes públicas de ensino contam com elevado número de professores contratados por tempo determinado. Mais de dois terços dos respondentes do primeiro survey da TDEBB não prestaram concurso para o desempenho de suas atividades.

\section{Os funcionários da educação básica pública nos planos de carreira}

A Meta 18 se refere à obrigatoriedade de criação ou reorganização dos planos de carreira dos profissionais da educação básica, logo tais planos deverão incorporar todos os profissionais da educação considerados na Lei nº 12.014, de 2009 já citada. Isso significa um grande desafio para muitas redes de ensino que, até o momento, apenas contemplam nos seus planos de carreira os profissionais do magistério, basicamente professores e especialistas, deixando de fora funcionários administrativos e de apoio.

Os funcionários de escola tiveram importantes conquistas nos últimos anos em relação ao reconhecimento de sua condição profissional e de garantias de certos direitos. Destaca-se entre essas conquistas o Programa de Formação Inicial em Serviço dos Profissionais da Educação Básica dos Sistemas de Ensino Público (Profuncionário). Criado a partir dos desdobramentos da Resolução no 5, de 22 de novembro de 2005, do Conselho Nacional de Educação que institui 21ํㅗ́rea de Educação Profissional (Área Profissional 
de Serviços de Apoio Escolar), o Profuncionário foi instituído por meio da Portaria normativa $\mathrm{n}^{\mathrm{o}}$ 25, de 31 de maio de 2007. Ele tem por objetivo formar os funcionários de escola, em efetivo exercício, em competências compatíveis com as atividades por eles desenvolvidas nos estabelecimentos de ensino.

O Decreto nํㅜ‥415, de 30 de dezembro de 2010, institui a Política Nacional de Formação dos Profissionais da Educação Básica e dispõe sobre o Profuncionário. Dentre seus objetivos, tal política visa à valorização do trabalho dos profissionais da educação, por meio da oferta de cursos de formação inicial em nível técnico proporcionados pelo programa. Essa foi uma conquista importante para a profissionalização dos funcionários de escola, porém, como afirmam Boudon e Bourricaud (1993: 453), " a palavra profissionalização é muito ambígua. Num primeiro sentido, pode-se tomá-la como sinônimo de qualificação. Mas essa qualificação está longe de estar sempre associada a uma competência técnica fundamentada num saber mínimo institucionalmente garantido".

Poucos são os estudos que lançam seus olhares sobre os funcionários de escola. $\mathrm{Na}$ realidade brasileira, carecemos de pesquisas mais amplas que possam contribuir para uma apreciação geral do que vivem esses funcionários nas distintas redes de ensino.

Em estudo exploratório realizado pela Confederação Nacional dos Trabalhadores em Educação (CNTE), em 2009, procurou-se, dentre outros objetivos, traçar um perfil do segmento de funcionários de escola, a partir da necessidade de se buscar um mínimo de conhecimento sobre a categoria, uma vez que não eram identificados censos específicos ou base de dados consistente nas estatísticas oficiais (Dourado e Moraes, 2009). De acordo com esse estudo, a distribuição dos funcionários de escola por sexo apresentou-se equitativa, sendo $50 \%$ dos entrevistados do sexo masculino e os demais, feminino.

A pesquisa TDEBB realizou, em Pernambuco, em 2013, um survey específico com os funcionários das unidades educacionais (creches e escolas) da rede estadual e 17 redes municipais, sendo entrevistados 612 funcionários das unidades de educação básica7 .

As redes de ensino investigadas em Pernambuco apresentaram um quadro bem distinto daquele observado no estudo exploratório realizado pela CNTE em 2009. No geral, três quartos (3/4) dos funcionários entrevistados afirmaram ser do sexo feminino. Ressalta-se que, na educação infantil e, consequentemente, na rede conveniada, da mesma forma que no grupo de docentes, o percentual de entrevistados do sexo feminino é superior, sendo $80 \%$ e $85 \%$, respectivamente.

A média de idade apresentada pelos funcionários das unidades educacionais em Pernambuco foi de 41 anos e meio, com metade dos indivíduos afirmando ter até 42 anos. Tal média corrobora o perfil traçado pelo estudo realizado pela CNTE em 2009, o qual indica que os funcionários de escola concentram-se, majoritariamente, nas faixas etárias acima dos 40 anos (Dourado e Moraes, 2009). As maiores médias de idade são observadas entre os funcionários que atuam em unidades educacionais que ofertam prioritariamente o ensino médio e, consequentemente, sob a jurisdição da rede estadual de ensino. E são 
percebidas, ainda, entre os indivíduos que atuam em municípios e estabelecimentos de ensino considerados de grande porte (neste último, são registradas médias de idade de 47 anos, com metade dos indivíduos afirmando ter até 49 anos) $)^{8}$.

Com relação aos aspectos socioeconômicos, observamos que, no que se refere ao salário bruto advindo da atividade exercida, metade dos entrevistados afirmaram ter um rendimento de até um salário mínimo ( $\mathrm{R} \$ 678,00$ em 2013), ainda que mais de 80\% desses indivíduos tenham uma carga horária de trabalho semanal acima de 30 horas.

As menores médias salariais são observadas entre os funcionários lotados em unidades educacionais conveniadas com a rede pública de ensino ( $R$ \$589,36) e que atuam em instituições que ofertam a educação infantil ( $\mathrm{R} \$ 737,96)$. As menores médias salariais são encontradas, ainda, entre os funcionários que atuam em unidades educacionais consideradas de pequeno porte ( $\mathrm{R} \$ 882,97)$, localizadas em municípios de igual tamanho ( $\mathrm{R} \$ 832,48)$. Contudo, ao considerar os diversos cenários, é importante ressaltar que, embora se observe os menores rendimentos entre os grupos de funcionários de unidades educacionais localizados nestes contextos, não pode ser considerada uma discrepância sua situação com a dos sujeitos inseridos nas outras. Analisando a mediana do salário bruto, observamos que a diferença não varia significativamente. Isto é, metade dos indivíduos entrevistados afirmou ter um rendimento mensal aproximado nos diversos contextos analisados.

Ainda que apresente percentual elevado de indivíduos concentrados nas menores faixas salariais, o número de funcionários de escola que se declararam o principal provedor de rendimentos do grupo familiar é cerca de dois terços (2/3) do público entrevistado. Nos cenários que agregam menores médias salariais e de rendimento familiar, mais da metade dos entrevistados informou que seus ganhos são tidos como a principal fonte de renda do grupo familiar, chegando esse percentual a representar mais de 2/3 em alguns desses contextos.

Os dados socioeconômicos dos funcionários das unidades educacionais obtidos na pesquisa mostram que, embora os cenários analisados apontem para uma desvantagem para o grupo de profissionais que atua nas unidades educacionais da rede conveniada, que concentra, majoritariamente, matrículas na educação infantil, consideradas de pequeno porte e localizadas em municípios com uma população de até 30 mil habitantes, trata-se de um público com um perfil bem homogêneo, além de muito distinto do corpo docente dessas unidades educacionais.

Quanto à sua formação profissional, o nível de escolaridade dos funcionários das redes de ensino pesquisadas apresentou-se concentrado na educação básica, sobretudo no ensino médio (incluindo aí o ensino médio normal e a educação profissional técnica de nível médio). Desse universo, apenas 15\% informaram ter concluído a graduação, sendo que 6,9\% afirmam, ainda, possuir cursos de pós-graduação. 
De acordo com os dados da pesquisa, embora o estado de Pernambuco seja considerado como um dos pioneiros na implantação do Profuncionário, a participação dos funcionários no programa tem sido baixa. Dentre os entrevistados, apenas $12 \%$ informaram participar ou ter participado dessa formação.

Sobre o tempo médio de trabalho dos entrevistados na área educacional, isto é, como funcionário das unidades educacionais (independente do tipo de vínculo ou contrato de trabalho e dependência administrativa dos estabelecimentos de ensino), é de 11 anos. No entanto, observa-se que metade desses profissionais informou ter, no máximo, seis anos de atuação na área.

Nos recortes aqui propostos, o grupo que atua em unidades educacionais que ofertam o ensino médio, apesar de não revelar um valor médio de tempo de trabalho muito acima dos grupos que atuam nas unidades educacionais que ofertam as demais etapas de ensino, apresentou um maior percentual de indivíduos nas faixas de tempo de serviço na área educacional superior a 20 anos. Nos demais cenários, as maiores médias de tempo de serviço concentram-se entre os profissionais que atuam em unidades educacionais sob a jurisdição do governo estadual, consideradas de grande porte e localizadas em municípios considerados de médio porte.

Considerando o tempo de atuação em uma mesma rede de ensino, os funcionários das unidades educacionais atreladas ao poder público estadual apresentam uma média superior aos profissionais que atuam nas demais redes (11 anos e meio).

O tempo de trabalho em uma mesma unidade educacional apresentou-se baixo no conjunto dos entrevistados em comparação à experiência profissional na área educacional e em uma mesma rede de ensino. Em média, os funcionários de escola apresentaram um tempo de trabalho no mesmo estabelecimento de ensino de seis anos e quatro meses, sendo que metade desse público afirmou ter até três anos de atuação na mesma unidade educacional. Sob este prisma, as maiores médias concentram-se entre os funcionários que atuam em unidades educacionais que ofertam o ensino médio e estão sob jurisdição do governo estadual pernambucano, localizadas em municípios considerados de grande porte e com um número de matrículas superior a 1.600.

Ao analisar o fato de os funcionários trabalharem em outra unidade educacional, fica evidente que a vinculação daqueles que trabalham nas redes estadual (94\%) e municipal (96\%) é quase em sua totalidade exclusiva. Entre aqueles que atuam na rede conveniada de ensino, o contrato com uma única unidade educacional é exclusivo, isto é, $100 \%$ dos entrevistados dessa rede informaram não atuar em outro estabelecimento de ensino. A taxa mais baixa de profissionais que trabalham em outras unidades educacionais é encontrada na educação infantil (4\%), quando comparada ao ensino fundamental $(6 \%)$ e ensino médio (6\%). Proporção maior $(11 \%)$ de funcionários que trabalham em outra instituição é obtida junto àqueles de unidades educacionais de grande porte (11\%). Também quando se considera o porte do município em que se encontram as unidades 
educacionais pesquisadas, funcionários de municípios grandes apresentam maior valor relativo $(7 \%)$ de profissionais que trabalham em outra instituição.

A função desenvolvida pelos funcionários é outra variável analisada no estudo e é classificada em três grupos: o primeiro constituído pelos auxiliares de serviços gerais, o segundo pelas merendeiras e o terceiro pelas demais funções. Os entrevistados da rede estadual são constituídos em $22 \%$, cada, por auxiliares de serviços gerais e merendeiras e $56 \%$ por funcionários das demais funções. Já na rede conveniada, observa-se a maior parcela de funcionários que atuam com serviços gerais (38\%). Proporções semelhantes de funcionários que atuam como auxiliar de serviços gerais, variando de $18 \%$ a $22 \%$, são verificadas nas três etapas de ensino. A categoria que se relaciona a outras funções é mais recorrente em unidades educacionais de grande porte (78\%) do que naquelas de médio porte (57\%) e de pequeno porte (50\%). Já quanto ao porte do município em que se encontram, há taxas semelhantes de auxiliares de serviços gerais, oscilando de $18 \%$ a $32 \%$.

Quando se observa o vínculo do funcionário em relação à dependência administrativa de que fazem parte, temos que $50 \%$ da rede municipal são concursados contra apenas $17 \%$ da rede estadual. Especificamente sobre a rede conveniada, o maior grupo (46\%) é de profissionais com carteira assinada (CLT), seguido por 15\% que são temporários ou substitutos e $23 \%$ que possuem outros vínculos. Levando em consideração a etapa de atendimento, os estatutários compreendem $47 \%$ dos entrevistados do ensino médio, $17 \%$ da educação infantil e $25 \%$ do ensino fundamental. Os estagiários com remuneração representam $11 \%$ dos profissionais da educação infantil e do ensino fundamental e $9 \%$ do ensino médio.

A relação entre o tipo de vínculo e o porte da unidade educacional dos funcionários aponta taxas de concursados equivalentes a $22 \%$, 23\% e $39 \%$, respectivamente, para os entrevistados de unidades educacionais de grande, médio e pequeno porte. Já os temporários ou substitutos representam $7 \%$ dos profissionais de unidades educacionais consideradas de pequeno e grande porte e de apenas $2 \%$ de unidades educacionais de médio porte. Ao considerar o porte do município, verifica-se que os estatutários totalizam 47\% dos entrevistados de municípios pequenos, 46\% de médios e 19\% de grande porte. Já os voluntários não chegam a 1\% dos entrevistados de municípios pequenos e médios, enquanto essa categoria representa $5 \%$ dos profissionais de municípios de grande porte.

A carga horária semanal do funcionário na unidade educacional em que foi entrevistado é outra variável utilizada para caracterizar as condições de trabalho desses profissionais. Aqueles que trabalham de 20 a 39 horas semanais nas instituições contabilizam 40\% dos entrevistados da rede estadual, 68\% da municipal e 52\% da conveniada. Já os que possuem carga acima de 40 horas por semana representam $57 \%$ dos sujeitos da rede estadual, $24 \%$ da rede municipal e $43 \%$ da conveniada. Por sua vez, quando se relativiza pela etapa de atendimento, os percentuais daqueles que trabalham 40 horas 
ou mais por semana nas unidades educacionais se equivalem a $26 \%$ para a educação infantil e o ensino fundamental e $59 \%$ para o ensino médio.

Os funcionários de unidades educacionais de pequeno porte que possuem carga horária semanal de 20 a 39 horas representam 57\% dos entrevistados, aqueles de instituições de médio porte $51 \%$ e os de instituições de grande porte $47 \%$. As taxas de entrevistados que trabalham 40 horas ou mais por semana representam $37 \%$, $41 \%$ e $53 \%$ dos funcionários de instituições pequenas, médias e grandes, respectivamente. Já quando se considera o porte do município em que eles se encontram lotados, 5\% dos entrevistados de municípios pequenos trabalham até 19 horas nas unidades educacionais contra 7\% daqueles de municípios médios e $6 \%$ de municípios grandes que se encontram nessa mesma situação.

\section{Comentários finais}

Diante da constatação dos estudos da Divap/Sase/MEC de que a organização dos planos de carreira dos profissionais da educação básica na atualidade é bastante dispersa e variada, evidenciando grande diversidade de critérios e formatos de planos, encontrando-se desde aqueles que contemplam o conjunto dos profissionais da educação quanto os que apenas referem-se aos profissionais do magistério, o desafio deve concentrar-se antes de tudo na interpretação mais ampla da lei, ou seja, incorporar o conjunto desses profissionais nos planos que serão criados ou reorganizados.

Contudo, incorporar o conjunto mais amplo deve significar também buscar compreender e dar visibilidade e concretude aos sujeitos que chegam às unidades educacionais na condição de novos docentes. A educação infantil não pode permanecer como o espaço do improviso, a extensão do espaço doméstico, o entre-lugar da educação. É necessário enfrentar as dificuldades orçamentárias, romper os preconceitos e superar a ignorância que têm predominado em muitas gestões e que acabam por considerar que para a educação das crianças não é necessário o rigor profissional e, portanto, é possível realizá-la em padrão mais baixo que a escola regular. A educação infantil, como primeira etapa da educação básica, precisa receber a mesma atenção que as demais e isso passa antes de tudo pelo reconhecimento de que os que atuam nela devem ser profissionalizados, formados e preparados para este fim. Semelhante observação podemos fazer com relação às unidades educacionais que adotam programas de tempo integral. Os docentes que atuam nesses programas ou nos chamados contraturnos precisam ser preparados e remunerados de forma adequada. Esses docentes ressentem-se do desprezo que sofrem dentro das próprias escolas em que atuam, evidenciando uma separação entre os que atuam no turno regular e os do contraturno. (Clementino, 2013). 
Esses novos docentes que permanecem invisíveis nas estatísticas oficiais e nas políticas públicas para educação não sendo, portanto, contemplados nos planos de carreira e salários dos profissionais da educação, também, muitas vezes, não são lembrados nas pautas sindicais.

O caráter de emergência trazido pela Meta 18 do PNE para uma exigência já bastante conhecida e reiterada em diferentes instrumentos na legislação vigente não deve ser menosprezado e impõe compromissos e responsabilidades que envolvem diferentes setores. A obrigação é dos gestores públicos, porém os sindicatos de trabalhadores da educação e especialmente a CNTE desempenham papel crucial nesse processo.

As tendências à flexibilização das carreiras não podem resultar em perda de direitos. As críticas que se fazem à carreira do tipo burocrático estão sempre associadas à propensão a que as organizações flexibilizem cada dia mais suas estruturas e a forma de ascensão, recorrendo sempre ao modelo da organização da empresa privada e sua eficiência. Esses modelos tendem a valorizar atributos pessoais, tais como criatividade, iniciativa, compromisso. É necessário desvelar o que está por trás dessas críticas, resistir à sedução do discurso motivacional e buscar construir alternativas que realmente rompam com as formas tradicionais já superadas, mas que apresentem adequações que são compatíveis com os sentidos do público.

Nesse sentido, o acúmulo produzido pelas pesquisas acadêmicas em nossas universidades poderá ser um grande subsídio à discussão.

Recebido em março de 2016 e aprovado em maio de 2016

\section{Notas}

1 Ver: http://pmdb.org.br/wp-content/uploads/2015/10/RELEASE-TEMER_A4-28.10.15-on-line.pdf

2 http://planodecarreira.mec.gov.br/index.php

3 Esta pesquisa contou com o apoio da SEB/MEC, por meio de um Plano de Cooperação com a UFMG.

4 Na educação infantil, a pesquisa considerou, na sua amostra, além das instituições públicas, aquelas conveniadas com o poder público.

5 Os sujeitos docentes foram definidos na pesquisa TDEBB como "os profissionais que desenvolvem algum tipo de atividade de ensino ou docência, sendo compreendidos pelos professores e por outros profissionais que exercem atividade de docência" (Oliveira e Vieira, 2010).

6 Pesquisa com docentes do $6^{\circ}$ ao $9^{\circ}$ ano realizada pela OCDE em mais de 30 países. No Brasil, o Inep é o responsável por sua aplicação.

7 Descrição mais completa desses dados bem como algumas análises podem ser encontradas em Oliveira e Vieira (2014). 
8 Além da dependência administrativa e da etapa de atuação na educação básica, o survey levou em consideração, na sua amostra, o porte do município: de 20.000 até 50.000 habitantes, de 50.001 até 100.000 habitantes e acima de 100.000, e, nas suas análises, o porte da instituição educacional (pequena, média e grande). Conferir: Oliveira e Vieira (2014).

\section{Referências}

BALASSIANO; M., VENTURA. E.C. e FONTES FILHO, J.R. Carreiras e Cidades: Existiria um Melhor Lugar para se Fazer Carreira? Revista de Administração contemporânea. vol.8 no.3 Curitiba July/ Sept. 2004

BOUDON, R. e BOURRICAUD, F. Dicionário crítico de sociologia. São Paulo: editora Ática, 1993.

BRASIL. Lei no 9.394, de 20 de dezembro de 1996. Estabelece as diretrizes e bases da educação nacional. Diário Oficial da União, Brasília, DF, 1996.

BRASIL. Lei no 11.738, de 16 de julho de 2008. Institui o piso salarial profissional nacional para os profissionais do magistério público da educação básica. Diário Oficial da União, Brasília, 16 jul. 2008.

BRASIL. Lei no 13.005, de 25 de junho de 2014. Aprova o Plano Nacional de Educação - PNE e dá outras providências. Diário Oficial da União, Brasília, DF, 26 jun. 2014.

BRASIL. Resolução nº 2, de 28 de maio de 2009. Fixa as Diretrizes Nacionais para os Planos de Carreira e Remuneração dos Profissionais do Magistério da Educação Básica Pública. Diário Oficial da União, Brasília, 28 mai. 2009.

CLEMENTINO, A. M. Trabalho Docente e Educação em Tempo Integral: Um estudo sobre o Programa Escola Integrada e o Projeto Educação em Tempo Integral. 2013.188 p. Dissertação (Mestrado em Educação) - Faculdade de Educação, Universidade Federal de Minas Gerais. Belo Horizonte, 2013.

CODO, W. Educação: carinho e trabalho. Petrópolis: Vozes, 3ํㅡㄹ edição, 2002.

DEMAILLY, L. Politiques de la relation: approche sociologique des métiers et activités professionnelles relationnelles. Lille: Septentrion, 2009.

DOURADO, L. F.; MORAES, K. N.. Funcionário de escola: indicadores e desafios. In: ESCOLA DE FORMAÇÃO DA CONFEDERAÇÃO NACIONAL DOS TRABALHADORES EM EDUCAÇÃO (ESFORCE) (Org.). Retratos da Escola, v. 3, n. 5, p. 413-436, jul.-dez. 2009.

DUBAR, C. (1997). A socialização: construção das identidades pessoais e profissionais. Lisboa, Porto editora.

DUARTE, Alexandre W. B. Porque ser professor? Uma análise da carreira docente na educação básica no Brasil. 2012. 169f. Dissertação (Mestrado em Educação) - Faculdade de Educação da Universidade Federal de Minas Gerais, Belo Horizonte, 2013.

ESTEVES, J. M. Mudanças Sociais e Função Docente. In: NÓVOA, A.(org) Profissão Professor. Porto. Portugal: Porto Editora; 1995.

FCC: FUNDAÇÃO CARLOS CHAGAS. Atratividade da carreira docente no Brasil: relatório preliminar. São Paulo: FCC, 2009. Disponível em: <http://revistaescola.abril.com.br/pdf/relatorio-finalatratividade-carreira-docente.pdf >. Acesso em: 20 set. 2010.

GATTI, B. A.; BARRETO, E. S. Professores do Brasil: impasses e desafios. Brasília: UNESCO, 2009. 
GATTI, B. A.; BARRETO, E. S.; ANDRÉ, M. E. D. A. Políticas docentes no Brasil: um estado da arte. Brasília: UNESCO, 2011.

GONÇALVES, G. B. B. Uso profissional da voz em sala de aula e organização do trabalho docente. 2003. 176p. Dissertação (mestrado). Programa de Pós-graduação da Faculdade de Educação da Universidade Federal de Minas Gerais, 2003.

JARDIM, R.; BARRETO, S. .M.; ASSUNÇÃO, A. A. Condições de trabalho, qualidade de vida e disfonia entre docentes. Caderno de Saúde Pública, v. 33, n.10, p. 2439-2461, 2007.

LEME, L. F. Atratividade do magistério para o ensino básico: estudo com ingressantes de cursos superiores da Universidade de São Paulo. 2012. 192 f. Dissertação (Mestrado em Educação). Faculdade de Educação da Universidade de São Paulo, São Paulo. 2012.

LESSARD, C.; KAMANZI, P. C.; LAROCHELLE, M. Le rapport au métier des enseignants canadiens: le poids relatif de la tâche, des conditions d'enseignement et des rapports aux éléves et à l'équipe-école. Revue Éducation et Sociétés, v. 2, n. 32, p. 155-171, 2013.

MALET, R. Former, réformer, transformer la main-d'œuvre enseignante ? Politiques comparées et expériences croisées anglo-américaines. Education et sociétés. 1/2009 (n²3) , p. 91-122

OECD, Organization for Economic Co-operation and Development. Le rôle crucial des enseignants : Attirer, former et retenir des enseignants de qualité. Aperçu. Paris: OCDE, 2005.

OECD, Organization for Economic Co-operation and Development. A Teachers' Guide to TALIS 2013: Teaching and Learning International Survey. Paris: OECD, 2014. Disponível em: http://www.oecd.org/ edu/school/TALIS-Teachers-Guide.pdf. Acesso: 09 mai. 2016.

OLIVEIRA, D. A. A nova regulação de forças no interior da escola: carreira, formação e avaliação docente. In: RBPAE - v.27, n.1, p. 25-38, jan./abr. 2011.

OLIVEIRA, D. A. A reestruturação do trabalho docente: precarização e flexibilização. Educação e Sociedade, v. 25, n. 89, p. 1127-1144, 2004.

OLIVEIRA, D.A. Educação básica: gestão do trabalho e da pobreza. Petrópolis: Vozes, 2000.

OLIVEIRA, D. A. VIEIRA, L. M.F. Trabalho docente na educação básica no Brasil. Base de Dados TDEBB/GESTRADO. Faculdade de Educação/UFMG. Belo Horizonte. 2010. Apoio SEB/MEC.

RODRIGUES, M. L. Sociologia das profissões. Oeiras: Celta Editora, 2002.

TENTI FANFANI, E. La condición docente. Siglo Veintiuno Editores: Buenos Aires, 2005. 


\section{Careers and a National Salary base for professionals in basic education}

ABSTRACT: To create or revise the career plans of education professionals is an urgent demand. This text provides information, derived from research on aspects underexplored in a school context and pays special attention to school employees. Thus, the last part is devoted to a description and discussion of data from a survey with school employees in a Brazilian state.

Keywords: Teaching career. Education professionals. School employees.

\section{Carrière et revenu minimum national pour les professionnels de l'éducation basique}

RÉSUMÉ: Créer ou revoir les plans de carriére des professionnels de l'éducation est une demande urgente. Ce texte fournit des informations, issues de recherches, sur des aspects peu étudiés du contexte scolaire et consacre une attention particulière aux fonctionnaires de l'école. Ainsi, la dernière partie est consacrée à la description et la discussion d'une enquête auprés de fonctionnaires d'école d'un état brésilien.

Mots-clés: Carrière des enseignants. Professionnels de l'éducation. Fonctionnaires de l'école.

\section{Carrera y mínimo salarial nacional para los profesionales de la educación básica}

RESUMEN: Crear o revisar los planes de carrera de los profesionales de la educación es una demanda urgente. Este texto presenta datos derivados de encuestas sobre aspectos poco analizados del contexto escolar y dedica especial atención a los empleados de escuelas. Así, dedica la última parte a la descripción y discusión de los datos de una encuesta realizada a empleados de escuelas en un estado brasileño.

Palabras clave: Carrera docente. Profesionales de la educación. Empleados de escuelas. 